\title{
LUT
}

University

\section{Identifying Strategies for Sustainable Entrepreneurship}

Rantala Tero, Saunila Minna, Ukko Juhani, Rantanen Hannu

This is a Author's accepted manuscript (AAM) version of a publication

published by Palgrave Macmillan, Cham

in Innovation for Sustainability

DOI: 10.1007/978-3-319-97385-2_12

Copyright of the original publication: (C) The Author(s) 2019

Please cite the publication as follows:

Rantala T., Saunila M., Ukko J., Rantanen H. (2019) Identifying Strategies for Sustainable Entrepreneurship. In: Bocken N., Ritala P., Albareda L., Verburg R. (eds) Innovation for Sustainability. Palgrave Studies in Sustainable Business In Association with Future Earth. Palgrave Macmillan, Cham

This is a parallel published version of an original publication. This version can differ from the original published article. 


\title{
CHAPTER 12
}

\section{IDENTIFYING STRATEGIES FOR SUSTAINABLE ENTREPRENEURSHIP}

\author{
Authors: Tero Rantala, Minna Saunila, Juhani Ukko \& Hannu Rantanen \\ Department of Industrial Engineering and Management \\ School of Engineering Science \\ Lappeenranta University of Technology
}

\begin{abstract}
This chapter focuses on strategies for sustainable entrepreneurship. This chapter increases the understanding of which sustainable innovation strategies are emphasised in different sustainable entrepreneurship strategies. In addition to the utilisation of different sustainable innovation strategies, the valuation of environmental, economic, and social sustainability factors and selected motivational factors is used to explain the content of the identified sustainable entrepreneurship strategies. This chapter identifies four clusters that describe strategies for sustainable entrepreneurship. The identified clusters were labelled as follows: (1) Trailblazers (solution-oriented innovators with a comprehensive sustainable entrepreneurship strategy), (2) Ride Sharers (business-oriented, positivethinking developers), (3) Cost Cutters (problem-oriented operators with a cost-cutting innovation strategy), and (4) Risk Avoiders (environmentally oriented current state stabilisers). By identifying these clusters, this chapter contributes to the growing stream research on the connection of sustainable innovation and sustainable entrepreneurship
\end{abstract}




\section{IDENTIFYING STRATEGIES FOR SUSTAINABLE ENTREPRENEURSHIP}

\section{INTRODUCTION}

Entrepreneurial action has traditionally been embodied in people's relationships with the material and social environment, and entrepreneurship has always consisted of discovering an opportunity (Shane and Venkataraman 2000). Sustainable business and sustainable entrepreneurship are continuously growing areas in modern society. Over the last few decades, the deterioration of the environment and its consequences for humanity have led to new government policies and changes in the legislative framework for private sector activities and businesses (Kiron et al. 2013). Although knowledge related to green innovation and eco-innovation seems to be growing (Franceschini et al. 2016; Schiederig et al. 2012), some notable gaps exist in our current understanding. For example, new innovation strategies are needed to support sustainable entrepreneurship. Oke et al. (2012) observed that little attention has been paid to the conditions under which innovation strategy execution is likely to be effective in enhancing innovation performance and, consequently, firm financial performance. Further, there is a lack of understanding of how different innovation strategies contribute to sustainable entrepreneurship strategies. To develop a better understanding of sustainable entrepreneurship, this chapter provides insights into (1) the utilisation of different sustainable innovation strategies and (2) the valuation of environmental, economic, and social sustainability factors in different sustainable entrepreneurship strategies. We argue that if the content of sustainable entrepreneurship strategies can be more precisely recognised and understood, then entrepreneurs will be able to enhance their businesses by 
focusing on the factors (for example, the reduction of energy consumption, costs, and waste) that enable these strategies.

This chapter contributes to this research gap by exploring the sustainable entrepreneurship strategies used among horse industry operators in Finland. Although the sustainable entrepreneurship strategies explored in this chapter are used in a single industry, we believe that the results are useful for other industry operators as well as academics. At the practical level, the context of the horse industry is not significantly different from that of other agriculture-related industries; therefore, we believe that the results can be utilised by different decision makers, agricultural industry operators, horse industry operators, energy producers, and many other stakeholder groups. For example, political decision makers can utilise the results by determining which factors they should concentrate on if they want to support certain sustainable entrepreneurship strategies. For academics, this chapter provides important and interesting insights into which sustainable innovation strategies and individual sustainability factors are emphasised in different sustainable entrepreneurship strategies.

\section{SUSTAINABLE ENTREPRENEURSHIP}

Sustainable entrepreneurship is a research area combining innovation, entrepreneurship, and sustainability (Sarkar and Pansera 2016; Schaefer et al. 2015; Schaltegger and Wagner 2011; Schaltegger et al. 2016). The literature on the interplay between entrepreneurship and sustainable development has addressed concepts such as environmental, social, and sustainable entrepreneurship. Each type of entrepreneurship provides a perspective on entrepreneurship as a process in which a business creates value 
beyond profit (Schaefer et al. 2015). Environmental entrepreneurship is motivated by earning money through solutions that solve environmental problems, whereas social entrepreneurship deals with achieving societal goals and securing funding (Schaltegger and Wagner 2011).

Sustainable entrepreneurship differs from environmental and social entrepreneurship because sustainable entrepreneurship focuses on entrepreneurial activities for sustainable development in a more comprehensive way, such as creating offerings that address environmental, social, and economic aspects simultaneously (Schaltegger and Wagner 2011; Stubbs 2016). Sustainable entrepreneurship can also be defined from a process perspective, which refers to the recognition, development, and exploitation of entrepreneurial opportunities in the context of social and environmental problems (Belz and Binder 2015; Lumpkin et al. 2013).

Similarly, Schaltegger et al. (2016, p. 268) defined sustainable entrepreneurship as "a sustainability mission-driven process of solving environmental and social problems of unsustainability by means of the exploration and exploitation of market opportunities created with innovative business models." Bocken et al. (2014) divided these possible business models into technological-, social-, and organisational-oriented models. However, Boons and Lüdeke-Freund (2013) concluded that in order to be sustainable, the value proposition must provide environmental, social, and economic value. Researchers have concluded that the process of sustainable entrepreneurship remains largely unexplored (Belz and Binder 2015; Lumpkin et al. 2013; Schaltegger et al. 2016), thus necessitating further research. In particular, the management perspective of sustainability transitions is needed to produce new methods for creating value through sustainability 
(Boons and Lüdeke-Freund 2013). Hence, despite the increasing amount of research on sustainable entrepreneurship (Sarkar and Pansera, 2016; Schaefer et al. 2015; Schaltegger and Wagner 2011; Schaltegger et al. 2016), little is known about the innovation strategies that characterise the different ways of creating business potential through sustainable entrepreneurship.

\section{INNOVATION STRATEGIES}

Over the past decade, societies and firms have become increasingly aware of the environmental, economic, and social pressures their activities face, and, particularly during the last five years, research on green innovation and its interplay with economic performance has expanded to increase the current understanding of the ways in which new services, technologies, and business models enable societies and individual organisations to become more sustainable (Boons and Lüdeke-Freund 2013; Boons et al. 2013; Rizos et al. 2016). In the long term, the sustainable development of firms requires the adoption of green innovations. Such innovations can be more effectively developed and adapted when they are built on business models (Boons et al. 2013) and successful innovation strategies. Ireland et al. (2009) found that firms need the right set of organisational factors that include strategy, resources, and skills to successfully exploit the entrepreneurial spirit and improve innovation performance. Thus, an innovation strategy adopted in response to changes in nature and society will strategise and deploy resources appropriately to improve firm sustainability (Oke et al. 2012). The adoption of innovation strategies may be related to the exploitation of new technologies or services, investment in new technologies, or participation in new business models. Innovation 
strategies related to utilisation and investment in technological innovations have been suggested as important solutions to several sustainability challenges, such as the utilisation of renewable energy and nutrient recycling (Long et al. 2016). Thus, technology-based innovation strategies can play an important role in achieving economic growth and sustainable development (Shrivastava et al. 2016).

The adoption of service innovations and service-related innovation strategies can be seen as an engine for the renewal and sustainable development of individual firms and whole industries and as a catalyst for economic growth (Snyder et al. 2016). The innovation strategies related to service innovations can be linked to product and process innovations (Snyder et al. 2016) that pay attention to customer's changing roles (Michel et al. 2008) and new business models (Hsieh et al. 2013).

Innovation strategies related to business model innovation can be seen to be an important part of the approach to sustainable business and improving firms' sustainability (Boons and Lüdeke-Freund 2013; Chesbrough 2010; Yang et al. 2016). Business model innovation strategies are not necessarily related to new technologies or services, but rather they are new ways of creating and delivering value to stakeholders (Yang et al. 2016). Moreover, while utilising innovation strategies related to new business models, a business model innovation itself can become the source of a competitive advantage that supports firms' sustainable development (Boons and Lüdeke-Freund 2013; Chesbrough 2010). Although the importance of the successful use of innovation strategies as part of the sustainable development of firms, industries, and societies has been recognised, little attention has been paid to innovation strategies for sustainable entrepreneurship. In summary, this chapter classifies sustainable innovation strategies in four groups: 
investment in new technologies, exploitation of new technologies, exploitation of services, and participation in a new business model.

\section{EMPIRICAL EXAMINATION OF SUSTAINABLE ENTREPRENEURSHIP}

Horse industry entrepreneurs have long struggled with profitability. Increased costs and environmental regulations have created challenges for entrepreneurs, and new strategies are needed to increase the profitability of their business. Many options could be integrated in the entrepreneurs' existing core businesses. For example, waste (horse manure) could be utilised as a material for soil improvement or as an input for energy production in biogas plants, or it could be sold as processed fertiliser. The utilisation options support renewable energy production targets and the objectives of the circular economy, such as nutrient recycling, hence providing various strategies for horse industry entrepreneurs to build a new business, create jobs, improve energy self-sufficiency, and reduce greenhouse gas emissions. This industry thus offers a fruitful setting to study innovation strategies for sustainable entrepreneurship.

\subsection{Data collection}

The data for this research was gathered using an Internet-based survey questionnaire in August and early September of 2016. The population for this research comprises horse industry operators (cluster sampling, see Zikmund et al. 2013) in Finland. In designing the questionnaire, the extant literature was used to formulate the survey items (Delai and Takahashi 2011; Khan et al. 2016; Mamede and Gomes 2014; Svensson and Wagner 2015); thus it may be considered tested and valid. The questionnaire consisted of 18 
questions, of which three were related to the background information of the participants. Nine of the questions were related to the participants' current operations, two were related to the current risks and cost risks of the operators, one was related to the utilisation of sustainable innovation strategies (presented in table 1), and one was related to the individual sustainability factors behind those innovation strategies (presented in table 2); there were also two open questions regarding future of the horse industry. An invitation to participate in the survey was e-mailed to 631 Finnish horse industry entrepreneurs. Of the e-mailed questionnaires, 580 reached the recipients, and 51 were returned to the researchers with return-to-sender messages, indicating that the informants' e-mail addresses were no longer valid. A week after the questionnaire was first e-mailed, the first round of reminders was sent, resulting in a response peak. A week after the first reminder, another round of reminders was sent. Two weeks later, the received data were screened. A total of 133 valid responses were received and analysed, representing a response rate of around $23 \%$. Responses were considered invalid and were excluded from the analysis if any of the following criteria was met: if most of the answered items included missing values, if it was obvious that the responses were deliberately incorrect throughout the survey, and/or if there were inconsistencies in the responses.

\subsection{Measurements}

To understand sustainable innovation strategies for sustainable entrepreneurship, the analysis in this research is based on the respondents' willingness to use innovation strategies and the sustainability factors behind these strategies. In addition, three background variables (size, costs, and distance to a large industry operator) were entered 
in the questionnaire. The items related to sustainable innovation strategies and sustainability factors were constructed based on the current literature and research on innovation and sustainable development. The variables for sustainable innovation strategy (exploitation of a new technology, investment in a new technology, exploitation of a new service, and participation in a new business) were measured with one item each. These strategies were identified from the literature and modified into items by the authors. Each strategy variable was measured on a 7-point Likert scale, with response options ranging from "Not willing" to "Extremely willing" to utilise the sustainable innovation strategy.

Individual sustainability factors (presented in Table 2) were used to describe and validate the utilisation of the sustainable innovation strategies. Each variable was measured on a 7-point Likert scale, with response options ranging from "Not significant" to "Very significant". For motivational factors to utilise the innovation strategies, current industry-specific risks and cost risks (in this context, risks related to handling and utilisation of horse manure) were measured on the same 7-point Likert scale, with response options ranging from "Not significant" to "Very significant".

\subsection{Cluster analysis results}

To explore the various sustainable entrepreneurship strategies used, cluster analysis was employed to group the horse industry entrepreneurs into homogenous categories based on the entrepreneurs' exploitation of different sustainable innovation strategies (Table 1): exploitation of a new technology (Shrivastava et al. 2016), investment in a new 
technology (Long et al. 2016), exploitation of a new service (Snyder et al. 2016), and participation in a new business (Yang et al. 2016).

Table 1. Cluster analysis results.

\begin{tabular}{llllll}
\hline Innovation strategy & Mean & & & \\
& Overall $(n=$ & Cluster 1 $(n=45)$ & Cluster 2 $(n=35)$ & Cluster 3 $(n=25)$ & Cluster 4 $(n=$ \\
& $133)$ & & & & $28)$ \\
\hline Exploitation of a new technology & 5.04 & 6.76 & 4.43 & 6.24 & 2.14 \\
Investment in a new technology & 3.69 & 5.78 & 2.80 & 3.76 & 5.88 \\
Exploitation of a new service & 4.99 & 5.76 & 5.49 & 2.46 & 2.25 \\
Participation in a new business & 4.49 & 6.51 & 4.83 & 2.80 & 2.29 \\
\hline
\end{tabular}

After the four clusters were identified, their characteristics (based on costs, firm size, and distance to large industry operators) were explored. In clusters 1 and 3, costs were larger than in the other two clusters. Small firms were mostly included in clusters 3 and 4 , whereas medium-sized firms were in clusters 1 and 2. Most of the firms that were farther from large industry operators were in cluster 1 , and the ones that were closer to large industry operators were in cluster 3.

In addition, the individual sustainability factors that influenced the sustainable entrepreneurship strategies were explored. Ten individual sustainability factors and two motivational factors (risks and cost risks) were explored for each cluster. Table 2 presents the sustainability and motivational factors for each cluster, as well as a summary of the most valued sustainability factors for each cluster. 
Table 2. The means of the sustainability factors in each cluster.

\begin{tabular}{lllllll}
\hline & Cluster 1 & Cluster 2 & Cluster 3 & Cluster 4 & Sig. & Null hypothesis \\
\hline Risks & 3.8000 & 2.6571 & 3.2917 & 1.7500 & .000 & Rejected \\
Cost risks & 4.3721 & 3.1143 & 4.0400 & 1.7778 & .000 & Rejected \\
Waste and emission reduction & 6.1818 & 5.1471 & 5.3913 & 5.3571 & .015 & Rejected \\
Improvement in hygiene & 6.0000 & 5.0882 & 5.0435 & 4.9286 & .007 & Rejected \\
Reduction of energy consumption & 6.6818 & 5.6667 & 6.0870 & 5.5000 & .000 & Rejected \\
Improvement in land use & 6.3636 & 5.6667 & 5.1739 & 5.8571 & .016 & Rejected \\
Job creation & 6.2955 & 5.5588 & 5.5652 & 4.9286 & .001 & Rejected \\
Health and safety improvement & 6.2045 & 4.9118 & 5.6522 & 4.9643 & .001 & Rejected \\
Cost reduction & 6.7500 & 6.4412 & 6.3043 & 5.4815 & .000 & Rejected \\
Increase in income & 6.6136 & 6.2941 & 5.6957 & 5.4286 & .000 & Rejected \\
Creation of indirect jobs & 6.1364 & 5.5000 & 5.4348 & 4.7500 & .001 & Rejected \\
Creation of new business & 6.2955 & 5.4706 & 4.9130 & 4.8929 & .000 & Rejected \\
\hline
\end{tabular}

Generally, the clusters valued many of the same sustainability factors. For example, cost reduction, reduced energy consumption, and increased income were among the most valued sustainability factors in every cluster. Entrepreneurs in clusters 1 and 2 valued a variety of sustainability factors equally (particularly environmental and economic factors). Social sustainability factors were pronounced in cluster 3, among other environmental and economic sustainability factors. The most valued factors among entrepreneurs in cluster 4 were in the environmental sustainability category, but economic sustainability was also among the most valued sustainability factors. 


\section{CHARACTERISTICS OF THE CLUSTERS}

\subsection{Cluster 1: Trailblazers}

This cluster consisted of 45 entrepreneurs and was the largest (33.8\% of all entrepreneurs). As motivational factors, current risks and cost risks were the most significant. The entrepreneurs' actual costs seem to be larger than average. This cluster includes more medium-sized firms than the other clusters, as well as firms far from other large industry operators. In response to the current challenges, these entrepreneurs seem to be extremely interested in possibilities for new business models to increase income and reduce energy consumption, which seem to them to have great potential for creating new businesses and indirect jobs. Their sustainable entrepreneurship strategy seems to be very comprehensive, and they seem willing to adopt best practices, no matter whether they are related to the exploitation of a new technology or investment, the exploitation of a new service, or participation in a new business. These entrepreneurs see innovations as possibilities for cost reduction, job creation, new business models, reduction of energy consumption, and improvement of land occupation. This cluster seems to be a group of entrepreneurs who face the most risk in their current operations but who also have the most comprehensive sustainable entrepreneurship strategy, and they want to adopt innovations to improve the economic, institutional, and environmental sustainability of their businesses.

\subsection{Cluster 2: Ride Sharers}

The sustainable entrepreneurship strategies of this cluster of 35 entrepreneurs do not have risks or cost as motivational factors. The entrepreneurs' costs are low, and the firms are 
small or medium-sized. Because they do not have significant risks or cost risks as a driver for strategies, their willingness to invest in new technologies seems very low. However, they seem to recognise the unutilised potential of the current situation of their businesses, and therefore, they are willing to use participation in new business as the main part of their sustainable entrepreneurship strategy. These entrepreneurs are interested in taking advantage of the current unutilised potential of their businesses if they can do so as part of other entrepreneurs' innovation activities. Because these entrepreneurs do not seem face risks in their current activities, the firms seem interested in economic and institutional sustainability factors.

\subsection{Cluster 3: Cost Cutters}

The sustainable entrepreneurship strategies of the 25 sustainable entrepreneurs in this group seem to be motivated by risks and cost risks. There were more small firms in this cluster. However, they are in close proximity to large industry operators, and thus, possibilities for cooperation with other operators exists. The difference between the entrepreneurs in this cluster and cluster 1 is their sustainable entrepreneurship strategy for handling current challenges and risks. Whereas the Trailblazers in cluster 1 seem to have a comprehensive sustainable entrepreneurship strategy to utilise best practices to create something new and ease the current situation, the entrepreneurs in this cluster seem uninterested in investing in new technologies or being part of a new business. Their motivation to utilise new innovations and innovation strategies seems to be cost cutting of the current risks. 


\subsection{Cluster 4: Risk Avoiders}

This cluster consisted of 28 entrepreneurs who do not seem to have any risks or cost risks as a motivational driver for their sustainable entrepreneurship strategies. The firms were either small or large. The main difference between the entrepreneurs in this cluster and those in cluster 2 is related to the unutilised potential of the current businesses. Whereas the entrepreneurs in cluster 2 seem to be interested in better utilisation of the current businesses, the entrepreneurs in cluster 4 either do not recognise the unutilised potential of their businesses or otherwise are not interested in utilising it. Therefore, they seem uninterested in using innovation strategies. Instead, they seem to be interested in developing their existing situation, and for that reason, they found environmental sustainability factors to be the most important ones.

\section{CONCLUDING REMARKS}

This chapter identified four clusters that describe strategies for sustainable entrepreneurship. The scientific novelty of this research lies in the description of the strategies entrepreneurs follow when they operate sustainable businesses. Cluster analysis was applied to the selected sustainable innovation strategies, and after that, clusters were identified based on groups of variables: background variables (cost, firm size, and distance to large industry operators), motivational factors (perceived risks and cost risks), and sustainability factors (environmental, social, and economic).

Based on the distinct patterns within the clusters exhibited by these variables, the clusters were labelled as follows: (1) Trailblazers (solution-oriented innovators with a comprehensive sustainable entrepreneurship strategy), (2) Ride Sharers (business- 
oriented, positive-thinking developers), (3) Cost Cutters (problem-oriented operators with a cost-cutting innovation strategy), and (4) Risk Avoiders (environment-oriented current state stabilisers). By identifying these clusters, this chapter contributes to the growing stream research on the connection between sustainable innovation and sustainable entrepreneurship.

As presented earlier in this chapter, many sustainable innovation options could be integrated into horse industry entrepreneurs' existing core businesses. One of the most interesting current options supporting renewable energy and nutrient recycling is biogas production. In biogas production, waste (e.g., horse manure) is utilised as an input in a biogas plant, creating process outputs (biogas and digestate) that can be utilised as energy or materials for soil improvement. To use sustainable innovations related to biogas production (e.g., technologies or input delivery services), horse industry entrepreneurs may need to facilitate collaboration among their operations. This is because the required level of investment might be too great for one or two entrepreneurs, and biogas plants might need more of the process input (horse manure) than the amount produced by a few entrepreneurs' operations. The cluster analysis presented in this chapter indicates that Trailblazers could act as leaders by taking the financial responsibility for the investments, and Ride Sharers could act, for example, to deliver the process input. Within the horse industry, these two clusters of entrepreneurs seem to be the groups most likely to use sustainable innovations.

The following are some concluding remarks regarding this chapter's contributions to the existing knowledge. First, this chapter showed that cost savings are one of the main 
drivers when sustainability and innovation are exploited simultaneously. Cost reduction was among the most valued sustainability factor in each cluster in this research. In addition, an increase in income was perceived as important by all clusters. This supports the previous definitions of sustainable entrepreneurship in which sustainable entrepreneurs have been considered as actors who contribute to solving social and environmental problems through a successful for-profit business.

Second, environmental sustainability is often documented as an additional characteristic of sustainable development. We observed that environmental valuation guides a business only after no considerable risks are caused by the operation. This outcome is realised through the importance of the environment as part of the sustainable entrepreneurship strategies of entrepreneurs in cluster 4 (Risk Avoiders). In the sustainable entrepreneurship strategies of the operators in cluster 4, current risks are not a motivational factor for a sustainable entrepreneurship strategy. As the entrepreneurs seem to be satisfied with their current situation, their motivation for future development seems to be environmental sustainability factors (e.g., improvement of land). These remarks support the environmental entrepreneurship literature, which has shown that a business is motivated by earning money through solutions that solve environmental problems. In the sustainable entrepreneurship strategies of those in cluster 3 (Cost Cutters), the importance of environmental sustainability factors (e.g., improvement of land or waste and emission reduction) was not highlighted. In the sustainable entrepreneurship strategies of those in cluster 3, current risks and cost risks related to businesses were motivational factors, but the strategies were mainly influenced by economic factors. 
Third, the greater importance of the utilisation of sustainable entrepreneurship strategies is related to the reduction of energy consumption. Our results confirm this proposition. This important aspect seemed to be highlighted in the strategies of those in clusters 1 (Trailblazers) and 3 (Cost Cutters). The willingness to reduce energy consumption among the entrepreneurs in cluster 1 seems to be related to economic and environmental factors, whereas the motivation of the entrepreneurs in cluster 3 seems to be economic. Thus, reducing energy consumption is a characteristic of a sustainable entrepreneurship strategy in general, rather than a specific feature of individual entrepreneurs. In other words, the possibility of minimising energy consumption assists entrepreneurs in delivering eco-friendly solutions and is perceived as a strategic issue. Another important reason for the utilisation of sustainable entrepreneurship strategies is the creation of new business and the development and adoption of business model innovations.

It is not possible or even necessary that all companies be Trailblazers with such a comprehensive sustainable entrepreneurship strategy. However, Trailblazers can be an example for companies that are willing to simultaneously reduce energy consumption and create new business. Environmental regulations motivate companies to move toward green innovations, and the governmental aspects of sustainable development include elements of pertinent legislation, policies enacted in a community, and political support for development. The chapter suggests that when preparing regulations, legislation, and policies, policy makers should become more familiar with Trailblazers and their possible followers. In this way, the conceptual and analytical discussion of operationalising sustainable development could be increased. Future research interest may be aimed 
towards understanding Trailblazers and potential Trailblazers in more depth in order to support and highlight the importance of environment and sustainable entrepreneurship in the field of innovation.

\section{REFERENCES}

Belz, Frank Martin, and Julia Katharina Binder. 2017. "Sustainable Entrepreneurship: A Convergent Process Model.” Business Strategy and the Environment 26(1):1-17.

Bocken, Nancy M. P., Samuel W. Short, Padmakshi Rana, and Steve A. Evans. 2014. “A Literature and Practice Review to Develop Sustainable Business Model Archetypes.” Journal of Cleaner Production 65:42-56.

Boons, Frank, and Florian Lüdeke-Freund. 2013. "Business Models for Sustainable Innovation: State-of-the-Art and Steps Towards a Research Agenda." Journal of Cleaner Production 45:9-19.

Boons, Frank, Carlos Montalvo, Jaco Quist, and Marcus Wagner. 2013. "Sustainable Innovation, Business Models and Economic Performance: An Overview”. Journal of Cleaner Production 45:1-8.

Chesbrough, Henry. 2010. "Business Model Innovation: Opportunities and Barriers." Long Range Planning 43(2):354-363. 
Delai, Ivete, and Sérgio Takahashi. 2011. "Sustainability Measurement System: A Reference Model Proposal.” Social Responsibility Journal 7(3):438-471.

Franceschini, Simone, Lourenço G. D. Faria, and Roman Jurowetzki. 2016. “Unveiling Scientific Communities about Sustainability and Innovation. A Bibliometric Journey Around Sustainable Terms.” Journal of Cleaner Production 127:72-83.

Hsieh, Jung-Kuei, Hung-Chang Chiu, Chih-Ping Wei, HsiuJu Rebecca Yen, and YuChun Cheng. 2013. “A Practical Perspective on the Classification of Service Innovations." Journal of Services Marketing 27(5):371-384.

Ireland, R. Duane, Jeffrey G. Covin, and Donald F. Kuratko. 2009. “Conceptualizing Corporate Entrepreneurship Strategy." Entrepreneurship Theory and Practice 33(1):1946.

Kesidou, Effie, and Pelin Demirel. 2012. "On the Drivers of Eco-Innovations: Empirical Evidence from the UK." Research Policy 41(5):862-870.

Khan, Eijaz Ahmed, Mohammed Naim A. Dewan, and Md Maruf Hossain Chowdhury. 2016. "Reflective or Formative Measurement Model of Sustainability Factor? A Three Industry Comparison." Corporate Ownership and Control 13(2):83-92. 
Kiron, David, Nina Kruschwitz, Martin Reeves, and Eugene Goh. 2013. "The Benefits of Sustainability-Driven Innovation.” MIT Sloan Management Review 54(2):69-73.

Long, Thomas B, Vincent Blok, and Ingrid Coninx. 2016. "Barriers to the Adoption and Diffusion of Technological Innovations for Climate-Smart Agriculture in Europe: Evidence from the Netherlands, France, Switzerland and Italy." Journal of Cleaner Production 112:9-21.

Lumpkin, G. T, Todd W. Moss, David M. Gras, Shoko Kato, and Alejandro S. Amezcua. 2013. "Entrepreneurial Processes in Social Contexts: How Are They Different, If at All?" Small Business Economics 40(3):761-783.

Mamede, Pedro, and Carlos F. Gomes. 2014. "Corporate Sustainability Measurement in Service Organizations: A Case Study From Portugal.” Environmental Quality Management 23(3):49-73.

Michel, Stefan, Stephen W. Brown, and Andrew S. Gallan. 2008. "Service-logic Innovations: How to Innovate Customers, Not Products." California Management Review 50(3):49-65.

Oke, Adegoke, Fred O. Walumbwa, and Andrew Myers. 2012. "Innovation Strategy, Human Resource Policy, and Firms' Revenue Growth: The Roles of Environmental Uncertainty and Innovation Performance.” Decision Sciences 43(2):273-302.Rizos, 
Vasileios, Arno Behrens, Wytze van Der Gaast, Erwin Hofman, Anastasia Ioannou, Terri Kafyeke, Alexandros Flamos, Roberto Rinaldi, Sotiris Papadelis, Martin HirschnitzGarbers, and Corrado Topi. 2016. "Implementation of Circular Economy Business Models by Small And Medium-Sized Enterprises (SMEs): Barriers and Enablers.” Sustainability 8(11):1212.

Sarkar, Soumodip, and Mario Pansera. 2017. "Sustainability-driven Innovation at the Bottom: Insights from Grassroots Ecopreneurs." Technological Forecasting and Social Change 114: 327-338.

Schaefer, Katrin, Patricia Doyle Corner, and Kate Kearins. 2015. "Social, Environmental and Sustainable Entrepreneurship Research: What Is Needed for Sustainability-asFlourishing?" Organization \& Environment 28(4):394-413.

Schaltegger, Stefan, Florian Lüdeke-Freund, and Erik G. Hansen. 2016. “Business Models for Sustainability: A Co-Evolutionary Analysis of Sustainable Entrepreneurship, Innovation, and Transformation.” Organization \& Environment 29(3):264-289.

Schaltegger, Stefan, and Marcus Wagner. 2011. "Sustainable Entrepreneurship and Sustainability Innovation: Categories and Interactions." Business Strategy and the Environment 20(4):222-237. 
Schiederig, Tim, Frank Tietze, and Cornelius Herstatt. 2012. "Green Innovation in Technology and Innovation Management-An Exploratory Literature Review." $R \& D$ Management 42(2):180-192.

Shrivastava, Paul, Silvester Ivanaj, and Vera Ivanaj. 2016. "Strategic Technological Innovation for Sustainable Development.” International Journal of Technology Management 70(1):76-107.

Snyder, Hannah, Lars Witell, Anders Gustafsson, Paul Fombelle, and Per Kristensson. 2016. "Identifying Categories of Service Innovation: A Review and Synthesis of the Literature.” Journal of Business Research 69(7):2401-2408.

Stubbs, Wendy. 2017. “Sustainable Entrepreneurship and B Corps.” Business Strategy and the Environment 26(3):331-344.

Svensson, Göran, and Beverly Wagner. 2015. "Implementing and Managing Economic, Social and Environmental Efforts of Business Sustainability: Propositions for Measurement and Structural Models." Management of Environmental Quality: An International Journal 26(2):195-213.

Yang, Miying, Steve A. Evans, Doroteya Vladimirova, and Padmakshi Rana. 2017.

"Value Uncaptured Perspective for Sustainable Business Model Innovation." Journal of Cleaner Production 140:1794-1804. 
Zikmund, William G. Barry J. Babin, Jon C. Carr, and Mitch Griffin. 2013. Business Research Methods. $9^{\text {th }}$ Edition. Cengage Learning. Mason, USA. 